\title{
Manufacturing of Electrolyte and Cathode Layers SOFC Using Atmospheric Spraying Method and Its Characterization
}

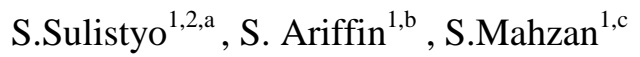 \\ ${ }^{1}$ Faculty of Mechanical and Manufacturing Engineering, UTHM, 86400 Batu Pahat, Johor, Malaysia \\ ${ }^{2}$ Energy Research Center Engineering Faculty, UNDIP, Tembalang, Semarang, Indonesia \\ ${ }^{\text {a)E-mail: listyotmeundip.ac.id; listyo2007@yahoo.com, }}$, s) sapareuthm.edu.my, \\ c) sharudin@uthm. edu.my
}

\begin{abstract}
The use of Solid Oxide Fuel Cell (SOFC) has created various interest in many parties, due to its capability to convert gases into electricity. The main requirement of SOFC cell components is to be produced as thin as possible to minimize the losses of electrical resistance, as well as able to support internal and external loads. This paper discusses the procedure of making a thin electrolyte layer, as well as a porous thin layer cathode using atmospheric spraying technique. The procedure of spraying was in room temperature with the process of sintering at temperature of $1^{1350^{\circ}} \mathrm{C}$ held for 3 hours. The SOFC characterization of electrolyte and cathode microstructure was determined by using the SEM, FESEM, XRD and impedance spectroscopy, to measure the impedance of SOFC cells. The results show that the thickness of thin layer electrolyte and porous cathode obtained of about $20 \mu \mathrm{m}$ and $4 \mu \mathrm{m}$, respectively. Also the SOFC cell impedance was measured of $2.3726 \times 10^{6} \Omega$ at room temperature. The finding also demonstrated that although the materials (anode, cathode and electrolyte) possess different coefficient thermal expansion, there was no evidence of flaking layers which seen the materials remain intact. Thus, the atmospheric spraying method can offer an alternative method to manufacturing of SOFC thin layer electrolyte and cathode.
\end{abstract}

[Key words: SOFC; spraying method; electrolyte; cathode]

\section{INTRODUCTION}

Solid Oxide Fuel Cell (SOFC) is an electrochemical device that converts the gas into electricity and waste products in the form of steam and heat if using hydrogen gas and operate between temperature $600-1000^{\circ}$ C. [1-3] The SOFC components consist of an anode, an electrolyte and a cathode. The anode serves as a gas catalyst, electrolyte serves as the medium to transfer negative ions from the cathode toward the anode, whereas the cathode serves as an oxidant catalyst.[4] One of the main requirements of SOFC cell components is be produced as thin as possible to minimize the losses of electrical resistance and able to support internal and external loads.[3] Several methods have been developed to produce a thin layer of electrolyte and porous cathode. These methods are grouped into chemical, physical and ceramic powders methods.[5, 6] Spraying technique is one of the methods that are categorised as physical methods. Several spraying techniques that have been used to create a thin layer are including thermal, flame spraying (FS), lowpressure plasma spraying (LPPS), DetoNation flame spraying (DFS) and high-velocity oxyfuel (HVOF) spraying. For examples, the plasma spraying technique is capable to produce the electrolyte and cathode with the respective thickness of 70 and 100 microns. Whereas, the thermal spray techniques has resulted the thickness ranges from 100-500 micrometers.[3, 5, 7] The main principle of spraying technique is by controlling the atomization of slurry or fluid and the droplets flow directed onto surface of the product. The cross sectional of the sprayed disk is affected by the air pressure, rheology of the slurry, design of nozzle and surrounding spreader, and working distance from the nozzle. 8, 9] The coating thickness on the substrate can be controlled by setting the cross-sectional of the spraying disk and this activity can be repeatedly done until the level of a certain thickness is achieved.[3,5]

\section{MATERIALS AND METHODS}

This investigation used YSZ powder with a nominal particle size around $2 \mu \mathrm{m}$ as the main component of electrolyte. The YSZ powder was mixed with ethanol, fish oil and a plasticizer with a weight ratio of 5: 94: 0.1:0.9 for YSZ, ethanol, fish oil and plasticiser, respectively. The material was stirred with ultrasound cleaner for 30 minutes. The solution was than measured with a vibro-viscometer. The electrolyte is then coated on porous NiO/YSZ anode disk through spraying method at room temperature. Spraying nozzle used hole size of $50 \mu \mathrm{m}$, air pressure 2.5 bar with a spray distance of $10 \mathrm{~cm}$. Spraying process is repeated for several times to obtain a required thickness. Material that has been coated is then placed in normal room for regular drying. The same procedure was repeated to create a layer of porous cathode. The LSM as cathode material was mixed with $95 \%$ ethanol; PEG, PVA, fish oil and cornstarch pore former. The weight ratios for each component are 5:93:0.6:1:0.1:0.3 for LSM, ethanol, PEG, 
PVA and cornstarch pore former, respectively. Sintering process is done at temperature of $1350^{\circ} \mathrm{C}$ for 3 hours. Material characterization used the Scanning Electron Microscope (SEM) and Field Emission Scanning Electron Microscope (FESEM) to observe the microstructure and thickness of the layers, whereas X-Ray Diffraction (XRD) was used to analyze peak diffraction and material compound. An impedance or gain phase analyzer complete with $\mathrm{PC}$ software $\mathrm{Z}$ view was used to analyze electrical impedance.

\section{RESULT AND DISCUSSION}

Spraying technique has greatly influenced on several aspects such as solution viscosity, spray pressure, spray holes and the distance between the spray and the substrate. To manufacture a thin film of electrolyte and cathode, the process selected solvent content of $95 \%$ ethanol and using fish oil dispersant. Table 1 shows the composition of each component for manufacture the electrolyte and cathode. Cathode solution is added with polyvinyl alcohol (PVA) binder and a pore-former cornstarch. Values for the viscosity of the electrolyte and the cathode solutions are presented in Table 2. However, the difference in the values of the viscosity is not significant, which is about 190 $\mathrm{mPa} . \mathrm{s}$; at the temperature of $23^{\circ} \mathrm{C}$.

Table 1: Composition of electrolyte and cathode

\begin{tabular}{|c|c|c|c|}
\hline No & Components & $\begin{array}{c}\text { Electrolyte } \\
(\mathrm{gm})\end{array}$ & $\begin{array}{c}\text { Cathode } \\
(\mathrm{gm})\end{array}$ \\
\hline 1 & YSZ powder & 5 & \\
\hline 2 & LSM powder & & 5 \\
\hline 3 & Ethanol 95\% & 94.5 & 93 \\
\hline 4 & PEG & & 0.6 \\
\hline 5 & PVA & 0.4 & 1 \\
\hline 7 & Cornstarch & & 0.3 \\
\hline 8 & Fish oil & 0.1 & 0.1 \\
\hline
\end{tabular}

Table 2: Viscosity of electrolyte and cathode

\begin{tabular}{|c|c|c|c|}
\hline No & $\begin{array}{c}\text { Electrolyte } \\
(\mathrm{mPa} . \mathrm{S})\end{array}$ & $\begin{array}{c}\text { Cathode } \\
(\mathrm{mPa} . \mathrm{S})\end{array}$ & Temperature \\
\hline 1 & 1.91 & 1.83 & $22.60 \mathrm{C}$ \\
\hline 2 & 1.89 & 1.86 & $230 \mathrm{C}$ \\
\hline 3 & 1.92 & 1.93 & $22.80 \mathrm{C}$ \\
\hline 4 & 1.90 & 1.94 & $22.80 \mathrm{C}$ \\
\hline 5 & 1.91 & 1.88 & $230 \mathrm{C}$ \\
\hline
\end{tabular}

A thin layer of electrolyte was attached to a disc-shaped anode material. Spraying process is repeatedly done to obtain a certain thickness. The cathode layer is sprayed on the dried electrolyte layer and then left to normal dry in room temperature. The disk that comprised of three layers of anode, electrolyte and cathode was then sintered in furnaces with temperatures of $1350 \mathrm{C}$ with holding time of 3 hours, and the rate of heat transfer is controlled at $1 \mathrm{C} /$ $\min$.

Figure 1 demonstrates the material characterisation of a SOFC obtained by the SEM. The SOFC cell thickness is measured of about 598 microns, shown in fig.1 (a), whereas the thickness of electrolyte and cathode were about 20 and
4 microns, respectively as shown in Fig. 1(b). The electrolyte layer was thicker than the cathode layer, caused by the repetition of the spraying process. The spraying on the electrolyte layer was 8 times, while the cathode layer was done for 3 times. However, other spraying parameters such as pressure and distance of spray were kept constant. (a)

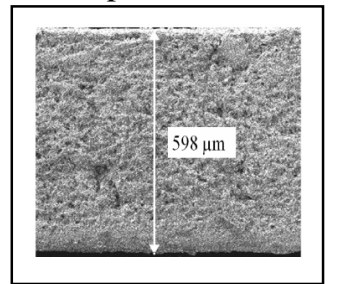

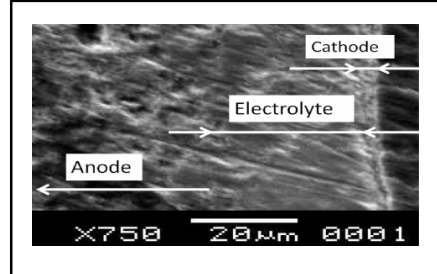

(b)
Fig. 1: Cross-sectional view of disk,

(a) Disk thickness, (b) Thickness of electrolyte and cathode

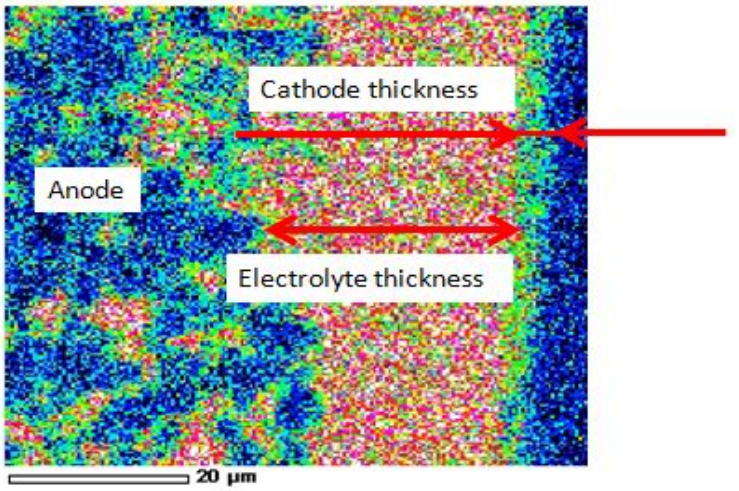

The main content of the electrolyte $\mathrm{Zr}$ atom

Fig.2. Cross-sectional view of electrolyte mapping

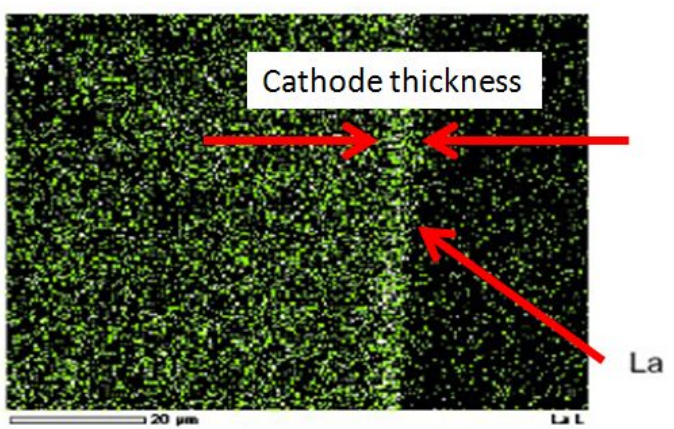

Fig.3. Cross-sectional view of cathode mapping

Microstructure mapping in Fig.2 and Fig.3 are shown to strengthen the argument for electrolyte and cathode layer thickness, described on Fig.1(b). Mapping results in Fig.2 indicated that the concentration of atoms contained in the electrolyte layer were Zirconium (Zr). While, Fig.3 shows the content contained in the cathode layer was Lanthanum (La). The thicknesses of the electrolyte layer and the cathode layer obtained through spray coating have a thickness that can be controlled. This process is very advantageous because of the thick and thin layers of electrolyte and cathode are greatly affecting the electrical properties, especially the electrical resistance.

Electrical resistance is defined as the ratio of the geometry of the flow path length to the cross-sectional area (L / A) divided by the electrical conductivity. Thus, to 
minimize the geometry ratio, the flow path length should be minimized as small as possible or to increase the crosssectional area as large as possible. These efforts are made to minimize the electrical resistance of SOFC cell by making the electrolyte and cathode layers as thin as possible.

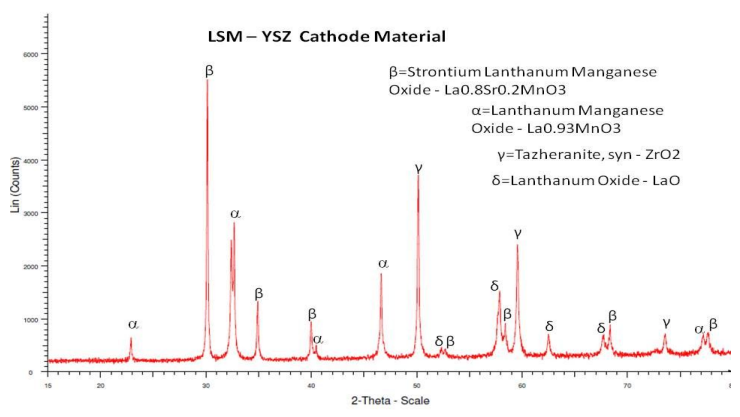

Fig.4. XRD pattern of cathode layer

Analysis on the composition of the thin layer was done using XRD diffraction, followed by using the EVA software to identify the compounds formed. The diffraction pattern of cathode layer obtained was shown in Fig.4. The results shows that the compounds formed were Lanthanum Strontium Manganese Oxide - La0.8Sr0.2MnO3, Lanthanum Strontium Manganese Oxide Sr0.1MnLa0.9O3 and Tazheranite, syn - ZrO2, Lanthanum Oxide - LaO.

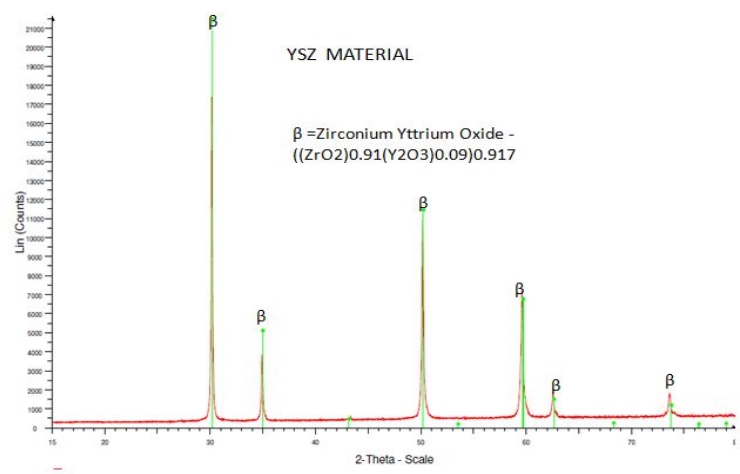

Fig.5. XRD pattern of electrolyte layer

The diffraction pattern for the electrolyte layer can be seen in Fig. 5. Compounds that were formed on the electrolyte layer were not as complicated as in the cathode. The compounds contained in the electrolyte layer is a compound of Zirconium Yttrium Oxide - ((ZrO2) 0.91 (Y2O3) 0.09) 0917. The formation of the compound in the electrolyte layer and the cathode layer provides information that there has been a process of diffusion between the particles making YSZ powder with elemental zirconium atom as the main material (Fig.3), while the LSM powders as cathode material contains several types of atoms, one of which is Lanthanum (La) (Fig.4).

SOFC cell impedance measurement was shown in Fig.6. From the impedance pattern, the resistance occurred in cells can be predicted. Total resistance was measured about $2.3726 \times 10^{6} \Omega$, whereas its capacitance was measured of about 4.0861 E-11 farrad.[12, 13]

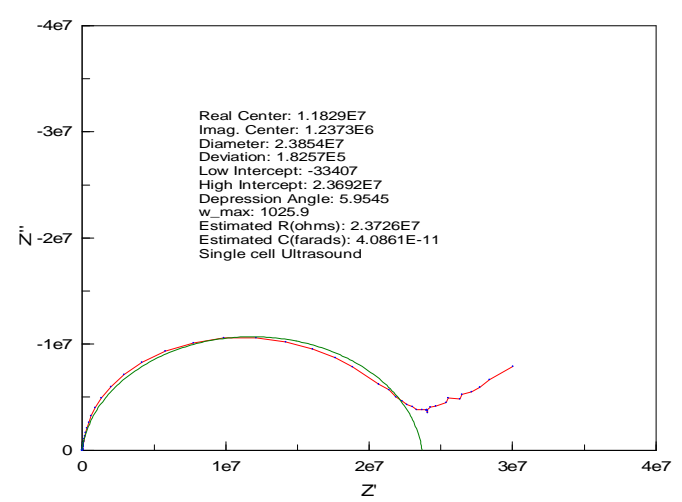

Fig.6. Impedance pattern of SOFC cell

The compounds are formed in each layer of electrolyte and cathode suggests that they are mutually bound to one another due to the sintering process at a temperature of 1350 C. In observation of microstructure (Fig.1) and mapping (Fig.2 and Fig.3), layers were attached to each other and there was no evidence of flaking layers despite three layers anode, electrolyte and cathode have different thermal expansion coefficients, the three layers remain united. $[10,11]$ A thin layer that occurs in the electrolyte and cathode were seen from the microstructure and mapping, layer formed quite well and strong, no one suffered delamination.

Although the materials used have different CTEs (coefficient thermal expansion), anode material NiO/YSZ is $13.1 \mathrm{E}-6 / \mathrm{K}$, electrolyte YSZ is $10.5 \mathrm{E}-6 / \mathrm{K}$ and cathode material LSM is $12.4 \mathrm{E}-6 / \mathrm{K}$, the different layers remain intact. [14, 15] Thus, the process of spraying at room temperature can be used as potential alternative manufacturing process of electrolyte and cathode thin layer followed by a sintering process with a controlled rate of heat transfer.

\section{CONCLUSION}

From the above discussion, it can be concluded as follows:

1. The quality of spraying process is strongly influenced by the viscosity of the solution, the substrate distance, hole sizes and spraying pressure.

2. The thin layers formed on the electrolyte and cathode using a spraying technique is 20 microns for electrolyte and 4 microns for the cathode.

3. The coating thickness of the electrolyte and cathode can be varied by repeated coating.

4. The quality of electrolyte and a cathode thin layer formed is strong enough and did not undergo any delamination. This condition can be done by controlling the rate of heat transfer during the process of sintering

\section{Acknowledgment}

The authors would like to thank Universiti Tun Hussein Onn Malaysia for supporting this research under the Postgraduate Incentive Research Grant. 


\section{REFERENCES}

[1]. Sylvio Savoie, T.W.N., Bertrand Morel, Michel Meunier, Réal Roberge, Catalytic activity of Ni-YSZ anodes in a single-chamber solid oxide fuel cell reactor. Journal of Power Sources, 2011. 196: p. 3713-3721.

[2]. Shiqiang (Rob) Hui, J.R., Sing Yick, Xinge Zhang, Cyrille DecesPetit, Yongsong Xie, Radenka Maric, Dave Ghosh, Review, A brief review of the ionic conductivity enhancement for selected oxide electrolytes. Journal of Power Sources, 2007. 172: p. 493-502.

[3]. Keegan C. Wincewicz, J.S.C., Taxonomies of SOFC material and manufacturing alternatives. Journal of Power Sources, 2005. 140: p. 280-296.

[4]. Li, X., Principles of Fuel Cells2006, Madison Avenue, New York, USA: Taylor \& Francis Group

[5]. J. Will, A.M., C. Kleinlogel,D. Perednis, L.J. Gauckler, Fabrication of thin electrolyte for second-generation solid oxide fuel cell. Solid State Ionic, 2000. 131: p. 79-96.

[6]. Fergus, J.W., Electrolyte for solid oxide fuel cells. Journal of Power Sources, 2006. 162: p. 30-40.

[7]. Lehnert, R.S.-W.a.W., Innovations in Fuel Cell Technologies. RSC Energy and Environment Series2010, Milton Road, Cambridge, UK: Royal Society of Chemistry.
[8]. Reed, J.S., Principles of Ceramics Processing1995, New York, USA: John Wiley \& Sons, Inc.

[9]. Rahaman, M.N., Ceramic Processing2007, Boca Raton, Florida, USA: CRC Press Taylor \& Francis Group.

[10]. Fergus, J.W., Oxide anode materials for solid oxide fuel cells. Solid State Ionic, 2006. 177: p. 1529-1541.

[11]. Wolf Vielstich, H.Y., Hubert A Gasteiger, Handbook of Fuel Cells Fundamentals Technology and Applications2009, Chichester, West Sussex, United Kingdom: John Wiley \& Sons.

[12]. Megel, S., et al., Area specific resistance of oxide scales grown on ferritic alloys for solid oxide fuel cell interconnects. Journal of Power Sources, 2011. 196(17): p. 7136-7143.

[13]. Toru Hatae, Y.m., Satoshi Yamashita, Yohtaro Yamazaki, Current density dependence of change in microstructure of SOFC anode during electrochemical oxidation. Solid State Ionic, 2009. 180: p. 1305-1310.

[14]. Kornely, M., et al., Degradation of anode supported cell (ASC) performance by Cr-poisoning. Journal of Power Sources, 2011. 196(17): p. 7203-7208.

[15]. Jiang, W., et al., Effect of Al2O3 film on thermal stress in the bonded compliant seal design of planar solid oxide fuel cell. Journal of Power Sources, 2011. 196(24): p. 10616-10624. 